\title{
CANARIAS-AMÉRICA. LOS ISLEÑOS DE LUISIANA Y DEL ENTORNO CARIBEÑO. II JORNADAS DEL IEHC PARA EL ESTUDIO Y DIFUSIÓN DE LA MÚSICA TRADICIONAL CELEBRADAS DEL 25 AL 27 DE OCTUBRE DE 2006 (TENERIFE, INSTITUTO DE ESTUDIOS HISPÁNICOS DE CANARIAS, 2020. 322 PP. + 1 CEDÉ CON 27 PISTAS)
}

\author{
José Manuel Pedrosa Bartolomé \\ Universidad de Alcalá
}

Fecha de recepción: 21/08/2021

Fecha de aceptación: 06/10/2021

Un libro sobre los contactos y trasvases de ida y vuelta de la música (y de la poesía tradicional y de la cultura) popular de las islas Canarias y de los países ribereños del Caribe que se inicia, como hace este, con un denso artículo acerca de las poblaciones y los oficios que migraron en siglos pasados de un lado del mar al otro, y que se cierra con otro profuso artículo acerca de los linajes que fueron, vinieron y se enredaron por acá o por allá, es un libro que está a todas luces concebido desde una vocación interdisciplinar, holística, que se sale de lo más previsible y trillado y desborda la promesa de su título, que apunta específicamente a la «música tradicional». ${ }^{1}$ No se conforma con ser una de tantas monografías al uso, centradas en un tema acotado, es más bien la feliz culminación de un programa ambicioso que quiere armar un marco histórico, sociológico, antropológico y etnográfico que haga más comprensible un patrimonio (etno)musicológico muy rico y cuyas ramas han crecido, durante siglos, por geografías muy dilatadas y en direcciones variables y muchas veces cruzadas: las de las músicas de raíz canaria dispersas por América.

Corrobora esas miras enciclopédicas en el mejor sentido del concepto el hecho de que las nueve «ponencias» que se dan cita en estas páginas, algunas muy extensas (la última tiene casi un centenar de páginas), y otras más breves pero muy intensas (las de los músicos que evocan sus propias tradiciones familiares y locales, por ejemplo) estén firmadas no por estudiosos de ocasión o de aluvión, como tantas veces y en tantos congresos sucede, sino por especialistas que llevan gran parte de sus vidas entregados a las investigaciones $y$, en algunos casos, al cultivo y la defensa militantes del patrimonio artístico propio.

El libro, que está editado de modo exquisito, no revela en las páginas de créditos los nombres de quienes tuvieron la generosidad de cuidar de que todas sus piezas (presentaciones,

\footnotetext{
${ }^{1}$ Descarga y audición libres desde http://www.iehcan.com/2021/07/canarias-america-los-islenos-de-luisiana-ydel-entorno-caribeno/.
} 
Enclaves. Revista de Literatura, Música y Artes Escénicas, n. ${ }^{\circ}$ 1, 2021, pp. 214-217. e-ISSN 2792-7350

José Manuel Pedrosa Bartolomé, «Canarias-América. Los isleños de Luisiana y del entorno caribeño. II Jornadas del IEHC para el estudio y difusión de la música tradicional celebradas del 25 al 27 de octubre de 2006», https://dx.doi.org/10.12795/enclaves.2021.i01.14

anexos, partituras musicales, apéndices documentales, cuadros, árboles genealógicos, grabaciones, etc.) encajaran donde correspondía, pero quienes conozcan las cualificaciones y las trayectorias de la etnomusicóloga Carmen Nieves Luis García y del historiador Manuel A. Fariña González no habrán de discurrir demasiado para deducir quiénes han estado detrás de que el resultado sea tan notable.

El hecho es que se trata de un libro (o de algo más que un libro, porque lleva veintisiete pistas de músicas asociadas) sumamente complejo, no solo en su contenido, sino también en su continente, por lo que ajustar su engranaje no ha debido de ser tarea fácil. El mérito añadido de que se pueda descargar de manera libre del portal del Instituto de Estudios Hispánicos de Canarias, que lo ha editado, y de que sus músicas puedan ser también escuchadas en el mismo portal confirma la generosidad de la aportación de cada uno de los estudiosos, editores, impulsores (el Grupo de Investigación de la Música Tradicional de Tenerife) e instituciones patrocinadoras (el Cabildo de Tenerife y los Ayuntamientos de San Cristóbal de La Laguna, Icod de los Vinos, La Guancha, San Juan de La Rambla, Tegueste y Los Realejos), que sumaron fuerzas para sacar este empeño a la luz.

Otra virtud digna de subrayado es que, aunque el libro atiende a todo el fenómeno de la migración social, cultural y musical de Canarias a América, algunas de sus partes más sustanciales están planteadas como un homenaje a los isleños, es decir, a los canarios y a los descendientes de los canarios establecidos históricamente en el estado norteamericano de Luisiana, y, de manera muy personal, a don Irvan J. Pérez, uno de los últimos y más cualificados portadores de la hoy muy menguante (puesto que va siendo absorbida por las culturas anglosajona y global) tradición isleña de Luisiana, quien iluminó con su presencia, con sus palabras y con sus cantos las jornadas académicas de las que emanó este libro. El señor Pérez fallecería a los 85 años de edad en 2008, dos años después de su último viaje a las islas de sus «antepadres» y de grabar las décimas y otros cantos con que deleitó a los concurrentes a las II Jornadas para el Estudio y Difusión de la Música Tradicional, cuyos frutos son ahora objeto de edición.

La ponencia inaugural («Algunos aspectos de la influencia de la cultura popular canaria en el mundo caribeño»), del historiador Manuel Hernández González, desentraña con minucia algunos de los vectores, trabajos y oficios manuales (en los ingenios azucareros, las labores de la piedra, las destiladeras, los molinos de mano, la cerámica, las construcciones de acequias y regadíos, la construcción y la carpintería, los campos de cacao) en que se ocuparon los canarios de condición subalterna emigrados durante varios siglos a América. El cuadro que presenta nos procura informaciones preciosas acerca de por qué vías y con qué individuos cruzaría también el mar la cultura tradicional de las islas.

En la ponencia segunda ( «Presencia de la música tradicional canaria en el área del Caribe. Algunas aportaciones»), Carmen Nieves Luis García traza un amplio y muy documentado fresco, remontándose a la renacentista danza del canario y atendiendo luego al zorongo, el carabiné, la isa, la jota, la fulía o la malagueña, de las presumibles influencias canarias en la música y en la danza popular de Puerto Rico, Santo Domingo, Venezuela y Cuba; apoya sus deslindes sobre una amplia y reveladora muestra de partituras musicales.

En la ponencia tercera («Mirada atlántica a través del objetivo canario-americano. La emigración isleña a Lusiana»), Manuel A. Fariña González arma una historiografía apabullante de la presencia de canarios y de la cultura canaria en la Luisiana estadounidense. Sobre la tradición oral de los isleños de aquellas tierras había escrito ya Samuel G. Armistead, en su monumental trabajo The Spanish Tradition in Louisiana Isleño Folkliterature (Newark: Juan de la Cuesta, 1992), pero Fariña se centra en el registro historicista que Armistead no abordó: 
Enclaves. Revista de Literatura, Música y Artes Escénicas, n. ${ }^{\circ}$ 1, 2021, pp. 214-217. e-ISSN 2792-7350

José Manuel Pedrosa Bartolomé, «Canarias-América. Los isleños de Luisiana y del entorno caribeño. II Jornadas del IEHC para el estudio y difusión de la música tradicional celebradas del 25 al 27 de octubre de 2006», https://dx.doi.org/10.12795/enclaves.2021.i01.14

en la migración, la instalación, la adaptación, la fidelidad a las raíces, el mantenimiento y la renovación de los lazos, incluso en el turismo que en las últimas décadas ha tendido puentes entre las Canarias y Luisiana.

La ponencia cuarta, de Irvan J. Pérez y Carmen Nieves Luis García, lleva el título de «La música tradicional de los isleños en San Bernardo, Luisiana». Ofrece una recuperación y una mirada diferentes, más centradas y más personales, sobre un patrimonio oral que ya había estudiado Armistead en su libro, pero que aquí tiene el mérito añadido de que es presentado en primera persona por el propio señor Pérez, quien fuera, por cierto, uno de los mejores informantes y amigos del gran estudioso norteamericano. Su ponencia en colaboración con Carmen Nieves Luis García tiene la sinceridad de lo autobiográfico y el rigor de lo académico.

Vienen después las ponencias de Antonio Ruiz Martín, «Panorama de la música tradicional canaria hoy. Algunas alternativas», que hace una minuciosa historiografía de la etnomusicología canaria, y de Víctor Cabrera Higuera, «Un recorrido por nuestra música tradicional canaria», que define algunas características de los primeros cantos y juegos, los cantos de trabajo, los ranchos y pascuas, las danzas, los instrumentos, las músicas de tambor y cuerdas, los cantos y bailes en general del repertorio cantado canario.

Gran interés y emotividad tienen las ponencias de José Manuel Ramos, «Acercamiento a la Punta del Hidalgo en su tradición musical», y de Olga C. Ramos, «El papel de la familia Ramos (Punta del Hidalgo, Tenerife) en la música tradicional canaria», que son las únicas del libro que no atienden a la proyección transatlántica del folclore musical canario. Ello se justificaba en que, como advierte la presentación del libro:

[...] ese año 2006 se cumplía el XXX aniversario de la muerte de Sebastián Ramos, uno de los más grandes cantadores de nuestra música tradicional. Además, durante generaciones, la familia Ramos ha sido un ejemplo de continuidad de un legado artístico y cultural, motivo más que suficiente para que se les rindiera un sentido homenaje y se difundiera su particular manera de interpretar el folclore canario, que en el caso de estas jornadas corrió a cargo, especialmente, de la sobrina de Sebastián Ramos, Olga Ramos y los hijos de ésta, Olga Catalina y José Manuel Ramos González. (10)

Que un congreso académico abra sus tribunas para que en ellas resuenen las voces, posiblemente más autorizadas que cualesquiera otras, de quienes nacieron en el seno de la tradición y son por ello sus mejores conocedores, no puede considerarse sino otra de las aportaciones más originales y valiosas del libro.

La última ponencia, la firmada por Carmen Nieves Luis García y Manuel A. Fariña González, lleva el título de «La música, nexo de unión entre los isleños de Luisiana y sus raíces familiares canarias», y es una minuciosísima al tiempo que monumental prospección genealógica, realizada sobre una prolija documentación de archivo, que logra enlazar apellidos, linajes y vínculos que los siglos diseminaron por geografías muy dispersas. La investigación se complementa con unos «Cuadros de los reclutados que salieron para Luisiana y árboles genealógicos» de alcances impresionantes.

El colofón (o el corazón) del libro lo pone una muy hermosa antología de músicas que permite escuchar once cantos en la voz irremplazable de Irvan J. Pérez, catorce entonados por miembros diversos de la familia Ramos (con instrumentistas acompañantes diversos) y dos por Fabiola Socas y Dacio Ferrera, con el timple de Domingo Rodríguez Oramas, El Colorado, y la guitarra de Juan Carlos Pérez Brito. Sus timbres, sus vibraciones, sus ritmos y su expresividad desbordantes dejan pálida cualquier información que pueda trasladar solo la letra, incluso la letra académica más documentada y comprometida, como es la que llena este libro 
Enclaves. Revista de Literatura, Música y Artes Escénicas, n. ${ }^{\circ}$ 1, 2021, pp. 214-217. e-ISSN 2792-7350

José Manuel Pedrosa Bartolomé, «Canarias-América. Los isleños de Luisiana y del

benemérito. Su escucha es una experiencia gozosa, pero también una llamada a la reflexión sobre la enorme pérdida que hemos sufrido de nuestro patrimonio musical y popular en general: el tesoro que ha persistido de estas músicas, tal como se nos regala en esta publicación, es, obviamente, una parte mínima del que estuvo vivo hace tan solo unas décadas; se trata, además, de una parte muy fragmentada y descontextualizada, puesto que las grabaciones sonoras no son capaces de dar cuenta de los gestos, las danzas, los contextos festivos y rituales, los paisajes que fatalmente se desvirtuaron o se perdieron.

Este libro tiene, pues, algo de homenaje y de celebración de la cultura canaria que se abrazó con la americana y algo de testamento de un patrimonio de cuyos esplendores pasados han quedado solo ecos muy tenues. Sin un libro como este, y sin empeños como los de sus promotores y participantes, hasta esos ecos se hubiesen perdido. 